\title{
Laser Produced Plasma X-Ray Sources for Nanoscale Resolution Contact Microscopy: A Candidate in Cancerous Stem Cells Imaging
}

\author{
Yas Al-Hadeethi1 ${ }^{1,2}$, A. Al-Mujtabi' ${ }^{1}$, Fahd M. Al-Marzouki ${ }^{1}$ \\ ${ }^{1}$ Physics Department, Faculty of Science, King Abdulaziz University, Jeddah, KSA \\ ${ }^{2}$ Lithography in Devices Fabrication and Development Research Group, DSR, King Abdulaziz University, Jeddah, KSA \\ Email:al_hadithi2001@yahoo.com
}

How to cite this paper: Al-Hadeethi, Y., Al-Mujtabi, A. and Al-Marzouki, F.M. (2017) Laser Produced Plasma X-Ray Sources for Nanoscale Resolution Contact Microscopy: A Candidate in Cancerous Stem Cells Imaging. Advances in Molecular Imaging, 7, 67-77.

https://doi.org/10.4236/ami.2017.74004

Received: October 18, 2017

Accepted: November 26, 2017

Published: November 29, 2017

Copyright $\odot 2017$ by authors and Scientific Research Publishing Inc. This work is licensed under the Creative Commons Attribution International License (CC BY 4.0).

http://creativecommons.org/licenses/by/4.0/

\begin{abstract}
Plasma X-ray sources for biological microscopy have been produced by focusing single shots from $\mathrm{Nd}$ :glass laser onto carbon rod targets at irradiances between $1 \times 10^{13} \mathrm{~W} \cdot \mathrm{cm}^{-2}$ and $3 \times 10^{13} \mathrm{~W} \cdot \mathrm{cm}^{-2}$ to expose test objects. The optimum parameters needed for obtaining high accurate information on the samples under test namely: the minimum energies and irradiances at a range of angles between the incoming laser beam and the normal to the resist, the depth of exposure of the photoresist as a function of incident laser energy (and irradiance) were concluded in this work.
\end{abstract}

\section{Keywords}

Laser Plasmas, Contact Microscopy, Laser Ablation, Water Window X-Rays, PMMA Photoresist, Mass Ablation Rate, Exposure Depth

\section{Introduction}

Plasma is formed when matter is brought to a highly ionized state by raising the temperature to a very high level typically for our considerations here between approximately $50 \mathrm{eV}$ and few $\mathrm{KeV}$. Natural sources such as stellar atmospheres and on earth, nuclear explosions or, in more controlled way tokomaks, pinch devices, sparks, and pulsed laser beams produce comparable temperatures within this range. Continuum emission in plasma can be produced due to Bremsstrahlung, from the Coulomb interactions between electrons and ions, and recombination radiation, when a free electron loses energy on recombination with an ion. A line spectrum is produced when an already bound electron loses energy by falling to a lower ionic energy state. 
The most common plasma X-ray sources are laser produced plasma (LPP) (single pulse and repetitive) and pinch plasmas.

The term soft X-ray (thus defined because of their low penetrating power) refers to electromagnetic radiation with a wavelength such that $1 \AA \leq \lambda \leq 300 \AA$ (or, in terms of photon energy $\mathrm{h} v, 300 \mathrm{eV} \leq \mathrm{h} v \leq 10 \mathrm{KeV}$ ). Hard X-rays below 1 $\AA$ are sometimes produced in plasmas due to highly accelerated electrons, such as runaway electrons in tokomak plasmas and supra thermal electrons in laser-produced plasmas colliding with solid material.

Studying the details of soft X-ray spectra, such as line intensities, line profiles and continuum intensities allows, for example, the determination of electron densities (by Stark broadening), ion densities (from absolute radiation intensities), electron temperature (using relative line ratios or continuum intensities) and ion temperatures (using Doppler broadening of spectral lines).

The potential of laser plasma X-ray sources is becoming increasingly evident, largely due to the rapid development of efficient lasers such as excimer-gas lasers and slab-geometry glass lasers. Proofs of principal, in which laser plasma X-ray sources were used to replicate sub-micron patterns, have already been made since the mid-eighties of the last century.

Neon-like ions have been of particular interest in research to develop X-ray lasers and in fact the first successful experiment producing soft X-ray lasing utilized neon-like Selenium ions which can be an excellent source for contact microscopy of living biological samples. On the other hand, evaluation of appropriate plasma parameters can be performed using spectroscopy of the emitted $\mathrm{X}$-rays as a diagnostic technique [1].

When high power pulses are focused on solid targets in vacuum, high density, high temperature plasmas are formed [2]-[7]. This paper will include only those details, which are relevant to the experiments undertaken. The theoretical treatment of laser plasma interactions is a complex, rapidly growing field.

Very little work has been performed to date on investigating the minimum energy (and irradiance) needed for single shot exposure of X-ray photoresists, using a laser produced plasma as an X-ray source as well as the characterization of the X-ray source itself. However, the need for such work has grown recently since such investigation is required for the techniques of soft X-ray contact microscopy and X-ray lithography. The use of high power pulsed lasers for soft $\mathrm{X}$-ray contact microscopy of both wet and dried biological material has already been reported since very long time [8] [9] [10]. VULCAN and SPRITE laser systems of the Central laser Facility at the Science and Engineering Research Council, Rutherford Appleton Laboratory (RAL) in England were used in these experiments. SPRITE of RAL, is a $\mathrm{KrF}$ excimer laser producing more than $200 \mathrm{~J}$ of ultraviolet radiation at a wavelength of $249 \mathrm{~nm}$ in a $50 \mathrm{~ns}$ pulse. VULCAN is an $\mathrm{Nd}$ :glass laser at RAL too, producing more than $150 \mathrm{~J}$ per beam at a wavelength of $1.05 \mu \mathrm{m}$ or about $50-70 \mathrm{~J}$ frequency doubled radiation at $0.53 \mu \mathrm{m}$ in $1 \mathrm{~ns}$ pulse [11]. The development of plasmas producing soft X-rays, using pulsed $\mathrm{KrF}$ 
$(0.6 \mathrm{~J})$ and $\mathrm{Nd}$ :YAG $(0.5 \mathrm{~J})$ lasers has also been investigated since very long [11]. In this paper, results are reported using a Q-Switched neodymium glass laser of pulses in the nano scale range and powers up to $10 \mathrm{GW}$. One of the advantages of this technique is its spatial resolution at the nanometre scale with a soft X-ray microscope. Spatial resolution can be below $10 \mathrm{~nm}$ which will be of other interests like for zone plate fabrication. This X-ray microscopy technique is therefore suitable for a wide range of studies; biological imaging in the water window [12]; studies of magnetic nanostructures with both elemental and spin-orbit sensitivity [12]; studies that require viewing through thin windows, and three-dimensional imaging of cryogenically fixed biological cells [13].

Interestingly, laser produced plasma X-ray sources approach, provide the capability to image nanostructures and chemical reactions down to nanometer resolution. This precision microscopy is due to mainly the short wavelengths, short living time of $\mathrm{X}$-rays and the ultrahigh-brightness of $\mathrm{X}$-rays using this source. Laser-produced plasmas (LPP) from carbon target, is becoming a hot topic of research for the last three decades due to its wide technological applications which include for example, diamond-like carbon (DLC) deposition and nanostructures production (carbon nanotubes, nanowires, and graphene) [14] [15].

Herne, it is proposed that this technique should be a good candidate for imaging cancerous stem cells. Cancer stem cells (CSCs) possess the ability to give rise to many different tumor cell types [16] [17]. They are responsible for the spread of cancer within the body-known as metastasis - that is responsible for $90 \%$ of cancer deaths [17]. "They also play a crucial role in the recurrence of tumors after treatment. This is because conventional radiation and chemotherapies only kill the 'bulk' cancer cells, but do not generally affect the CSCs." Cancer stem cells differentiate to form a small mass of cells known as a tumor-sphere. Accordingly, there is a need to detect, then to target and neutralize cancer stem cells in order to prevent or treat a wide range of cancers.

\section{Experimental Arrangements}

The experimental set-up of this work is shown in Figure 1 which consists of the following.

\subsection{Target Chamber}

The target chamber was made of aluminum and a perspex lid. The lowest attainable pressure was $2 \times 10^{-5}$ Torr, which was quite sufficient for the reported experiments. The internal diameter of the chamber was $27 \mathrm{~cm}$ and the distance from port was measured to be $29 \mathrm{~cm}$.

\subsection{Chamber Mount and Resist Chamber}

A mount was designed to hold the resist holder with the following specifications:

1) An adjustable height between $13.5 \mathrm{~cm}$ and $20 \mathrm{~cm}$. 


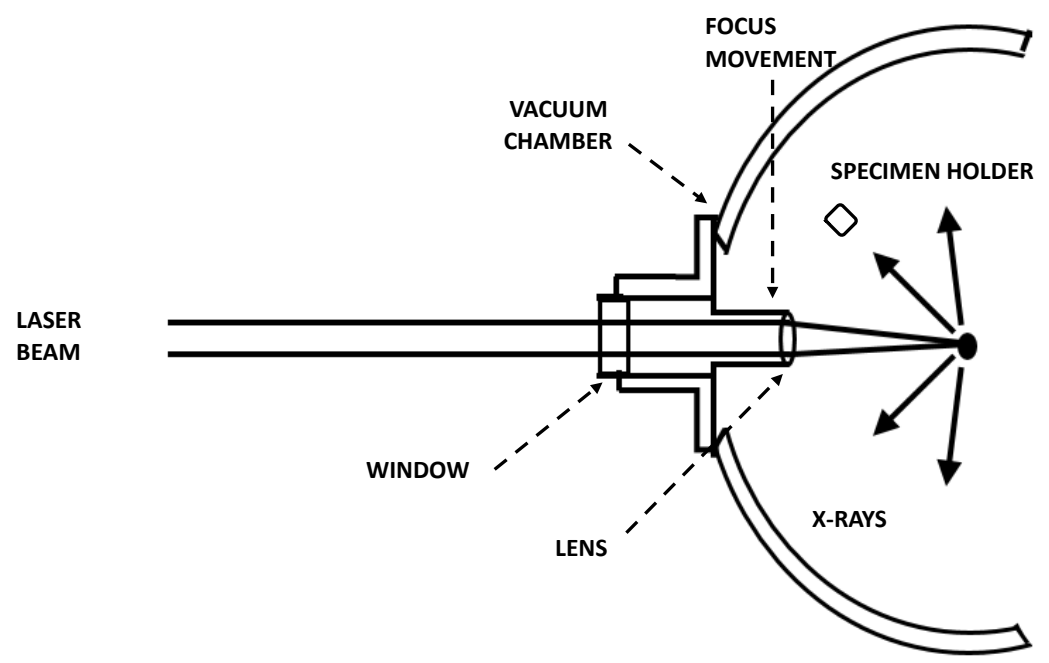

Figure 1. Experimental arrangement.

2) The possibility of mounting the resist chamber on the mount (see Figure 2 and Figure 3).

3) Capability of being rotated to angles of greater than 70 degrees, and at the same time being moved in the vertical direction in such a way as to allow the resist chamber to be positioned at the required distance from the target.

4) Possible adjustment of the resist distance by the resist chamber so the positioning at the required distance from the target can be achieved.

The chamber mount is finally attached to round base plate bolted to the vacuum chamber.

\subsection{Target}

Carbon was chosen as the target material to produce X-rays in the water window. This is due to the fact that carbon simplifies the interpretation and evaluation of the experimental results due to its low atomic number. It is also an easily obtainable material, and more than one shot can be fired onto the same target. Rotating carbon rod target provide a new fresh X-ray target.

The target holder holds the target surface normal to the direction of the incident laser beam. Furthermore, because of its low $\mathrm{z}$, quantitative interpretation of the spectral lines is correspondingly mush easier. Further advantage in using carbon target, its relatively high conversion efficiency from lasers to X-rays, particularly in the so-called water-window X-rays.

\subsection{Lenses}

The laser beam was focused on the carbon target using an $f / 2.5$ lens with a focal length of $60 \mathrm{~mm}$ mounted on a travelling base, and was made of silica. The best focusing position was found by using an infrared viewer. This was performed when the CW. Nd:YAG laser beam used for alignment was reflected from the target and directed by a $100 \%$ reflectivity mirror onto the viewer entrance window. Looking through the viewer, one can see the image of the focal spot onto 


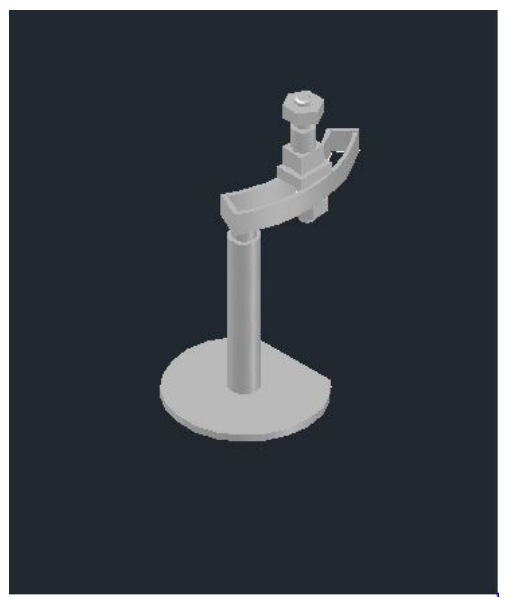

Figure 2. The resist chamber mount designed and constructed during this work.

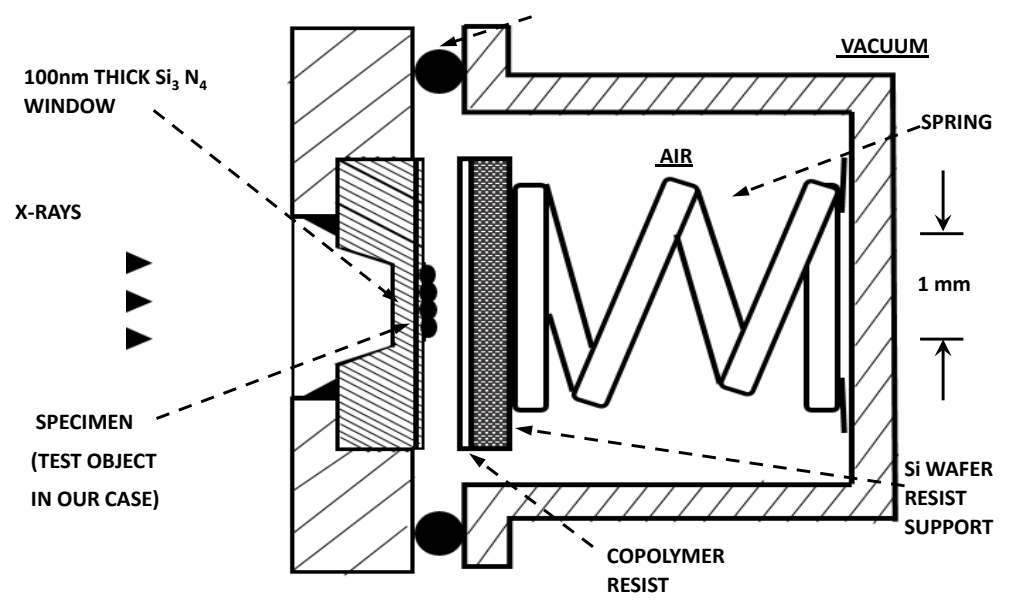

Figure 3. The resist chamber.

the target and by moving the target backwards and forwards, the best focusing position of the system (i.e. the smallest spot size) can be found. A focusing monitor (IR viewer) was used every time that a new carbon target was installed. A reflectivity loss of $8 \%$ for the focusing lens had earlier been measured by others. Two anti-reflection lenses were used for the target alignment.

\section{Results}

Single shot soft X-ray micrographs have been obtained using X-ray radiation produced by carbon plasmas generated by small laser. The Nd:glass laser produces a maximum energy of $10 \mathrm{~J}, 3-6 \mathrm{nsec}$ pulses at $1.06 \mu \mathrm{m}$ wavelength. The produced plasma emitted sufficient soft X-rays in the $2-5 \mathrm{~nm}$ wavelength to expose the resist in a single shot. Exposures were obtained with minimum energies and irradiances at a range of source to sample separations and a range of angles between the incoming laser beam and the normal to the resist as shown in Tables 1-4. A direct exposure (before resist development) was sometimes produced, probably, due to ultraviolet (UV) light rather than X-rays. Further analysis 
Table 1. SOURCE TO SAMPLE SEPRATION $=8-10 \mathrm{~mm}$. IPA: isopropanol MIBK: isobutyl ketone ECA: ethyl cello solve acetate.

\begin{tabular}{|c|c|c|c|c|c|c|}
\hline $\begin{array}{c}\text { LASER } \\
\text { Energy } \\
\text { E/(J) } \pm 10 \%\end{array}$ & $\begin{array}{c}\text { Mean } \\
\text { Irradiance } \\
\left(\mathrm{W} \cdot \mathrm{cm}^{-2}\right) \times 10^{12}\end{array}$ & $\theta /$ degrees & $\begin{array}{c}\text { Relative } \\
\text { Flux incident } \\
\text { at sample } \mathrm{E} / \mathrm{L}^{2} \\
\left(\mathrm{Jcm}^{2}\right)\end{array}$ & $\begin{array}{l}\text { Type and time } \\
\text { of development }\end{array}$ & $\begin{array}{c}\mathrm{Si}_{3} \mathrm{~N}_{4} \\
\text { Window } \\
\text { used }\end{array}$ & Notes \\
\hline 0.36 & 0.76 & $8^{\circ}$ & 0.44 & ECA for 2 mins & Yes & I \\
\hline 0.5 & 1.06 & $19^{\circ}$ & 0.6 & $\begin{array}{l}\text { 1:1 MIBK + IPA } \\
\text { for } 2 \text { mins }\end{array}$ & Yes & I \\
\hline 2.1 & 4.46 & $39^{\circ}$ & 2.6 & ECA for 5 mins & Yes & $\begin{array}{l}\text { Still nothing seen } \\
\text { on resist }\end{array}$ \\
\hline 0.5 & 5.3 & $59^{\circ}$ & 3 & ECA for 5 mins & Yes & $\begin{array}{l}\text { Still nothing seen } \\
\text { on resist }\end{array}$ \\
\hline 0.9 & 2.8 & $32.5^{\circ}$ & 1.1 & $\begin{array}{l}\text { 1:1 MIBK + IPA } \\
\text { for } 2 \text { mins }\end{array}$ & No & $\begin{array}{c}\text { Removing } \mathrm{Si}_{3} \mathrm{~N}_{4} \\
\text { Window allowed } \\
\text { a much lower } \\
\text { energy to expose } \\
\text { Resist }\end{array}$ \\
\hline 1.4 & 5.9 & $14^{\circ}$ & 1.73 & $\begin{array}{l}\text { 1:1 MIBK + IPA } \\
\text { for } 2 \text { mins }\end{array}$ & No & $\begin{array}{c}\text { Removing } \mathrm{Si}_{3} \mathrm{~N}_{4} \\
\text { window allowed } \\
\text { a much lower } \\
\text { energy to expose } \\
\text { Resist }\end{array}$ \\
\hline
\end{tabular}

Table 2. The different parameters used with angle $\theta=19^{\circ}$.

\begin{tabular}{cccc}
\hline $\begin{array}{c}\text { Laser Energy } \\
\mathrm{E} /(\mathrm{J}) \pm 10 \%\end{array}$ & $\begin{array}{c}\text { Mean irradiance } \\
\left(\mathrm{W} \cdot \mathrm{cm}^{-2}\right) \times 10^{12}\end{array}$ & $\begin{array}{c}\text { Depth of Exposure } \\
\mu \mathrm{m} \times 10^{-1}\end{array}$ & $\mathrm{Si}_{3} \mathrm{~N}_{4}$ Window used \\
\hline 1.98 & 4.2 & 0.5 & Yes \\
2.1 & 4.4 & 0.7 & Yes \\
302 & 6 & 1.4 & Yes \\
\hline
\end{tabular}

Table 3. The different parameters used with angle $\theta=14^{\circ}$.

\begin{tabular}{cccc}
\hline $\begin{array}{c}\text { Laser Energy } \\
\mathrm{E}(\mathrm{J}) \pm 10 \%\end{array}$ & $\begin{array}{c}\text { Mean Irradiance } \\
\left(\mathrm{W} \cdot \mathrm{cm}^{-2}\right) \times 10^{12}\end{array}$ & $\begin{array}{c}\text { Depth of Exposure } \\
\mu \mathrm{m} \times 10^{-1}\end{array}$ & $\mathrm{Si}_{3} \mathrm{~N}_{4}$ Window used \\
\hline 7.6 & 19.3 & 1.2 & Yes \\
5.8 & 14.7 & 1 & Yes \\
3.7 & 9.4 & 0.8 & Yes \\
1.4 & 5.6 & 1.1 & No \\
6.8 & 27.3 & 2 & No \\
5.9 & 23.8 & 1.8 & No \\
5 & 21 & 1.6 & No \\
4.5 & 19 & 1.6 & No \\
\hline
\end{tabular}

to measure the depth of exposure of the photoresist as a function of incident laser energy (and irradiance) has been carried out using the technique of TENCOR ALPHA-STEP measurement. The results are shown in Figures 4-8 and Tables 1-5. 
Table 4. The different parameters used with angle $\theta=8^{\circ}$.

\begin{tabular}{cccc}
\hline $\begin{array}{c}\text { Laser Energy } \\
\mathrm{E}(\mathrm{J}) \pm 10 \%\end{array}$ & $\begin{array}{c}\text { Mean irradiance } \\
\left(\mathrm{W} \cdot \mathrm{cm}^{-2}\right) \times 10^{12}\end{array}$ & $\begin{array}{c}\text { Depth of Exposure } \\
\mu \mathrm{m} \times 10^{-1}\end{array}$ & $\mathrm{Si}_{3} \mathrm{~N}_{4}$ Window Used \\
\hline 1.6 & 6.4 & 0.8 & Yes \\
2 & 8.5 & 1.2 & Yes \\
1.2 & 5.8 & 1.8 & Yes \\
1.6 & 6.8 & 0.9 & Yes \\
0.8 & 1.7 & 2.8 & Yes \\
\hline
\end{tabular}

Table 5. The different parameters used with angle $\theta=32.5^{\circ}$.

\begin{tabular}{cccc}
\hline $\begin{array}{c}\text { Laser Energy } \\
\mathrm{E}(\mathrm{J}) \pm 10 \%\end{array}$ & $\begin{array}{c}\text { Mean Irradiance } \\
\left(\mathrm{W} \cdot \mathrm{cm}^{-2}\right) \times 10^{12}\end{array}$ & $\begin{array}{c}\text { Depth of Exposure } \\
\mu \mathrm{m} \times 10^{-1}\end{array}$ & $\mathrm{Si}_{3} \mathrm{~N}_{4}$ Window Used \\
\hline 0.9 & 0.095 & Yes \\
1.8 & 0.17 & Yes \\
& 6 & 0.21 & No \\
& 2.9 & 0.225 & Yes \\
& 0.99 & 0.237 & Yes \\
2 & & 0.27 & No \\
17 & 7 & 0.29 & No \\
18 & 6.3 & 0.33 & No \\
23 & & 0.34 & No \\
& & 0.4 & No \\
& 6.8 & 0.41 & No \\
\hline
\end{tabular}

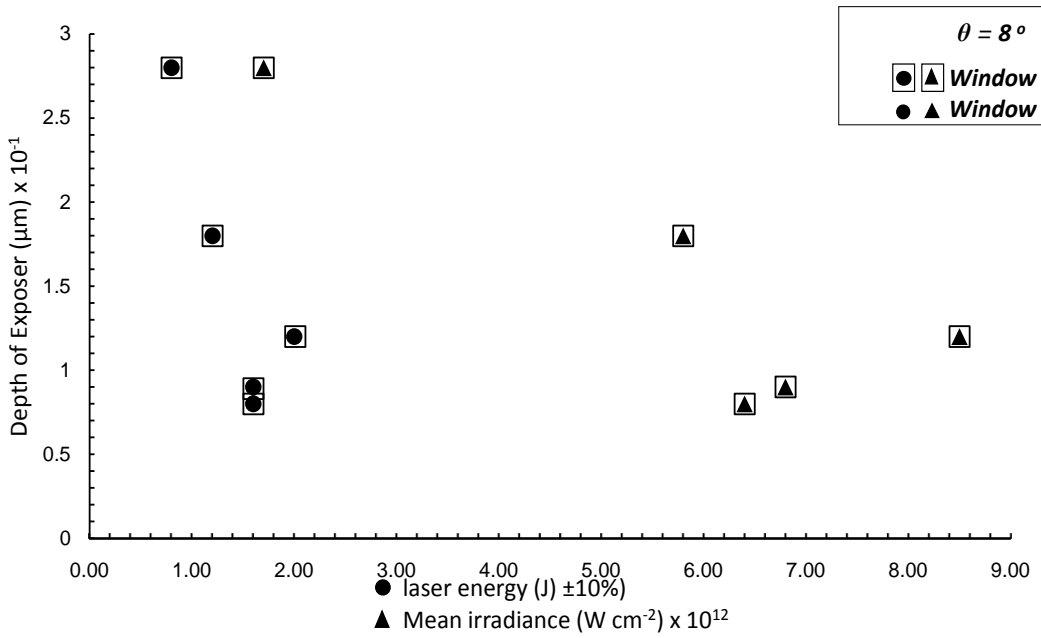

Figure 4. Depth of exposure as a function of laser energy $(\bullet)$ and laser irradiance $(\boldsymbol{\Delta})$ for both cases when using $\mathrm{Si}_{3} \mathrm{~N}_{4}$ window and without window at angle between the incoming laser beam and the normal to the resist $\theta=8^{\circ}$. 


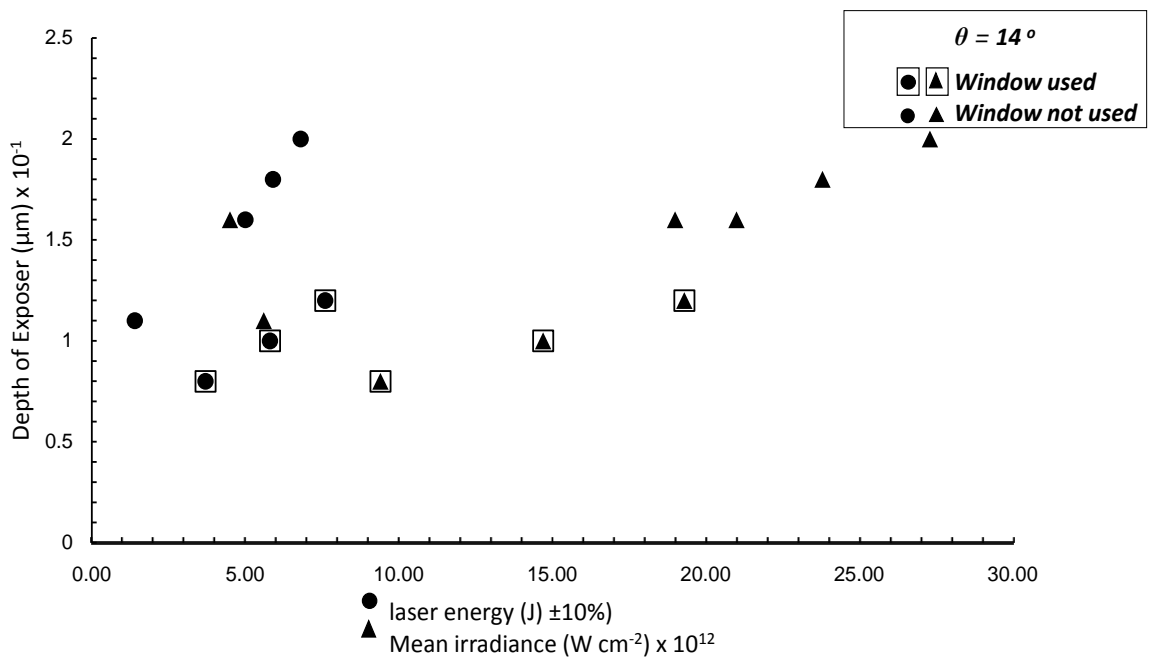

Figure 5. Depth of exposure as a function of laser energy $(\bullet)$ and laser irradiance $(\boldsymbol{\Delta})$ for both cases when using $\mathrm{Si}_{3} \mathrm{~N}_{4}$ window and without window at angle between the incoming laser beam and the normal to the resist $\theta=14^{\circ}$.

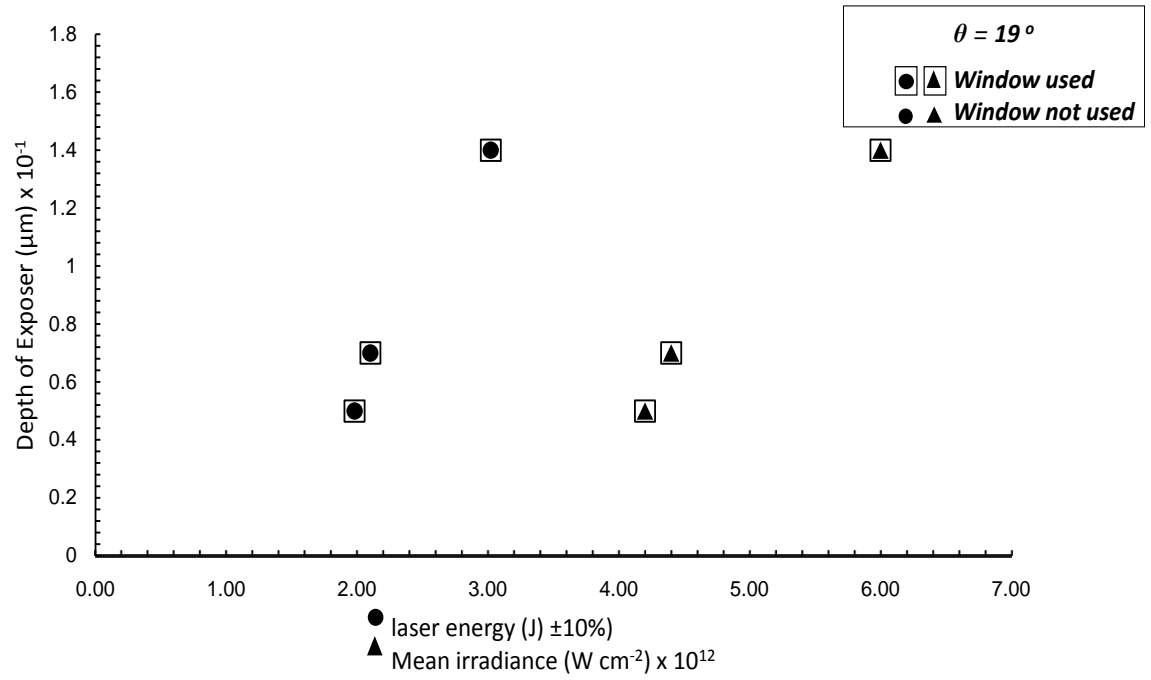

Figure 6. Depth of exposure as a function of laser energy $(\bullet)$ and laser irradiance $(\boldsymbol{\Delta})$ for both cases when using $\mathrm{Si}_{3} \mathrm{~N}_{4}$ window and without window at angle between the incoming laser beam and the normal to the resist $\theta=19^{\circ}$.

Depth of exposure and incident laser energy for angles $\theta=32.5^{\circ}, 8^{\circ}, 19^{\circ}, 14^{\circ}$ is shown in Figure 8. To estimate the "expected" pressure on the carbon rod target, the following relation between the laser parameters and the induced pressure on the irradiated carbon was used [18]:

$$
P(\text { Mbar })=8.6\left(\frac{I\left(\mathrm{~W} / \mathrm{cm}^{2}\right)}{10^{14}}\right)^{2 / 3} \lambda^{-2 / 3}\left(\frac{A}{2 Z}\right)^{1 / 3}
$$

Results are shown in Figure 9.

The carbon target mass ablation rate $\dot{m}$, can be estimated if the penetration depth, $d$, and the time of burn through $\mathcal{T}$ are known, viz. 


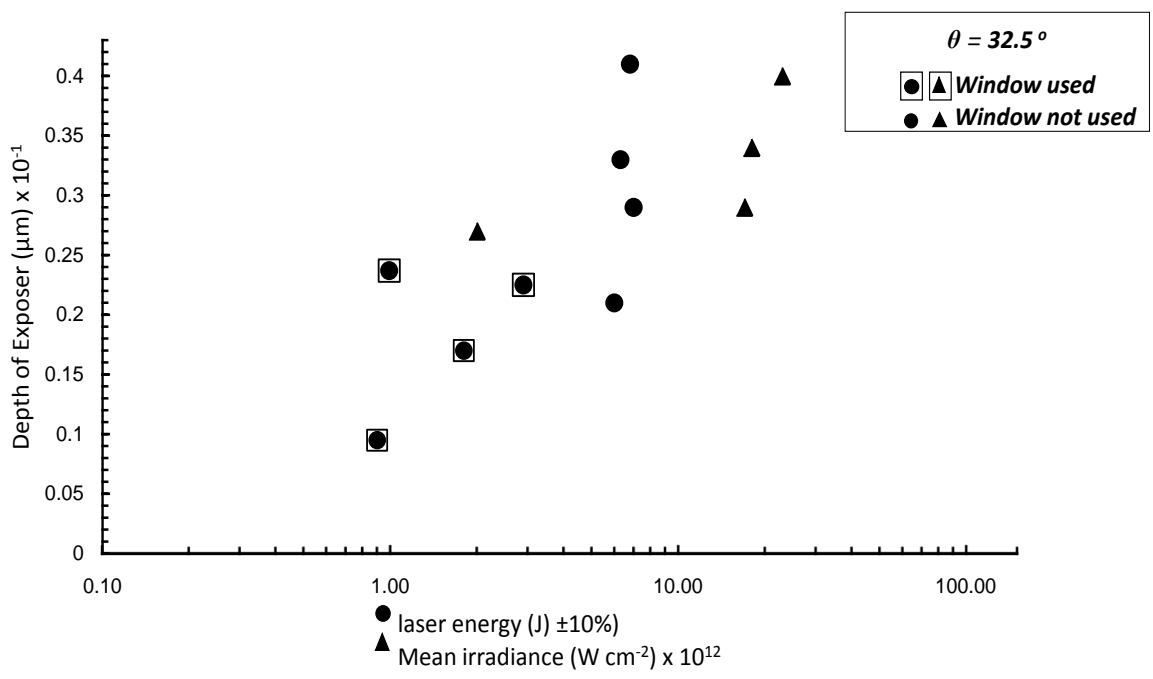

Figure 7. Depth of exposure as a function of laser energy $(\bullet)$ and laser irradiance $(\boldsymbol{\Delta})$ for both cases when using $\mathrm{Si}_{3} \mathrm{~N}_{4}$ window and without window at angle between the incoming laser beam and the normal to the resist $\theta=32.5^{\circ}$.

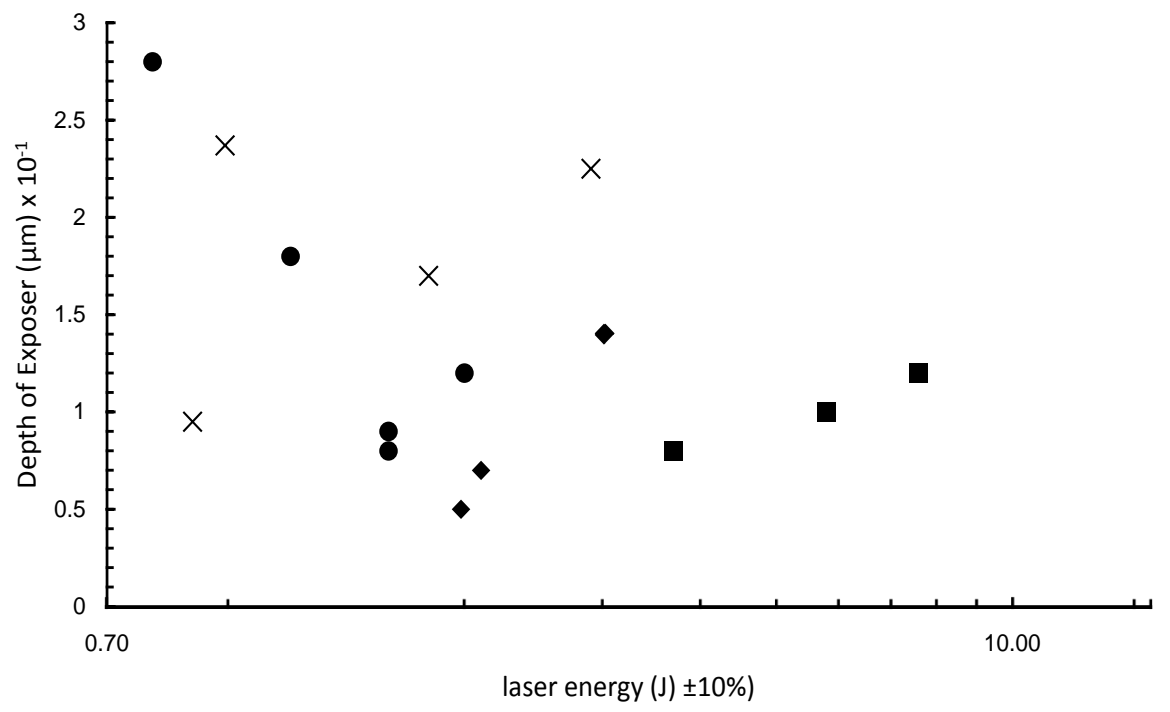

Figure 8. Comparing Depth of exposures \& Incident laser energy for angles $\theta=32.5^{\circ}, 8^{\circ}$, $19^{\circ}, 14^{\circ}$ represented by symbols $\mathrm{X}, \bullet, \bullet, \bullet$ respectively.

$$
\dot{m}=\rho \frac{d}{\mathcal{T}}
$$

Calculated results are shown in Figure 10.

\section{Conclusion}

This paper demonstrates the feasibility of using $\mathrm{Nd}$ :glass laser plasmas as sources of soft X-rays, and the capability of the contact imaging technique using such sources. A small glass laser was found capable of producing adequate levels of exposure. Further, this work can help to estimate how large a laser is needed for contact microscopy application when taking into account the source to specimen 


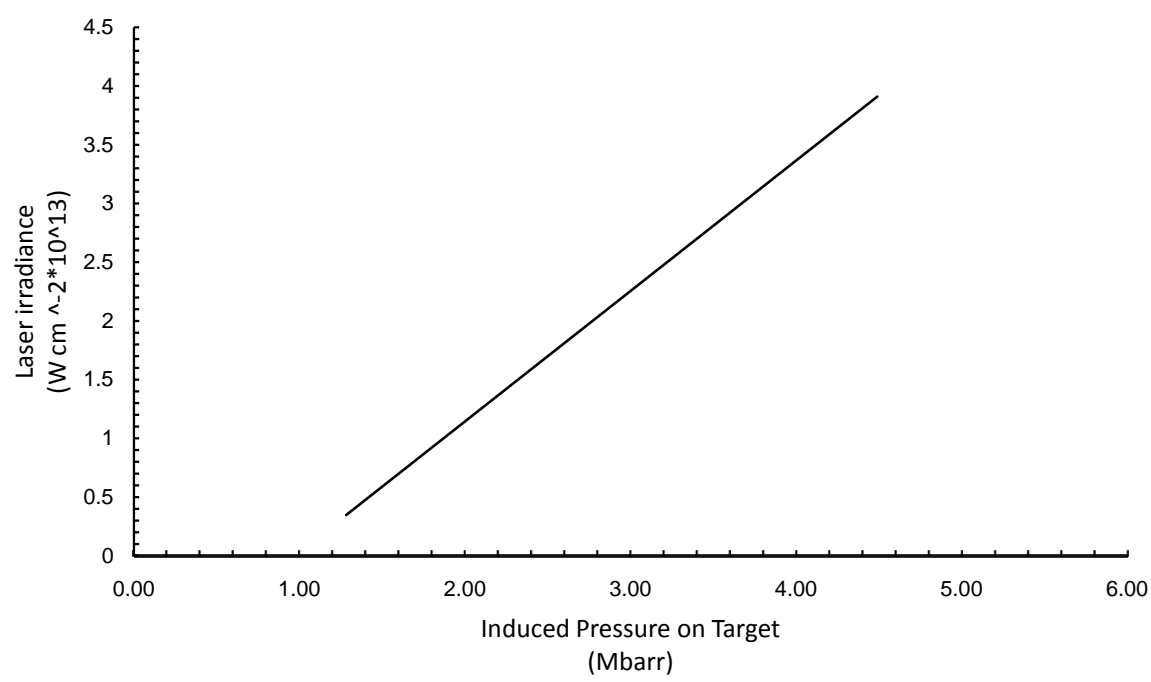

Figure 9. The "expected" pressure on the carbon rod target, using a relation between the laser parameters and the induced pressure on the irradiated carbon (Fabbro et al. 1985).

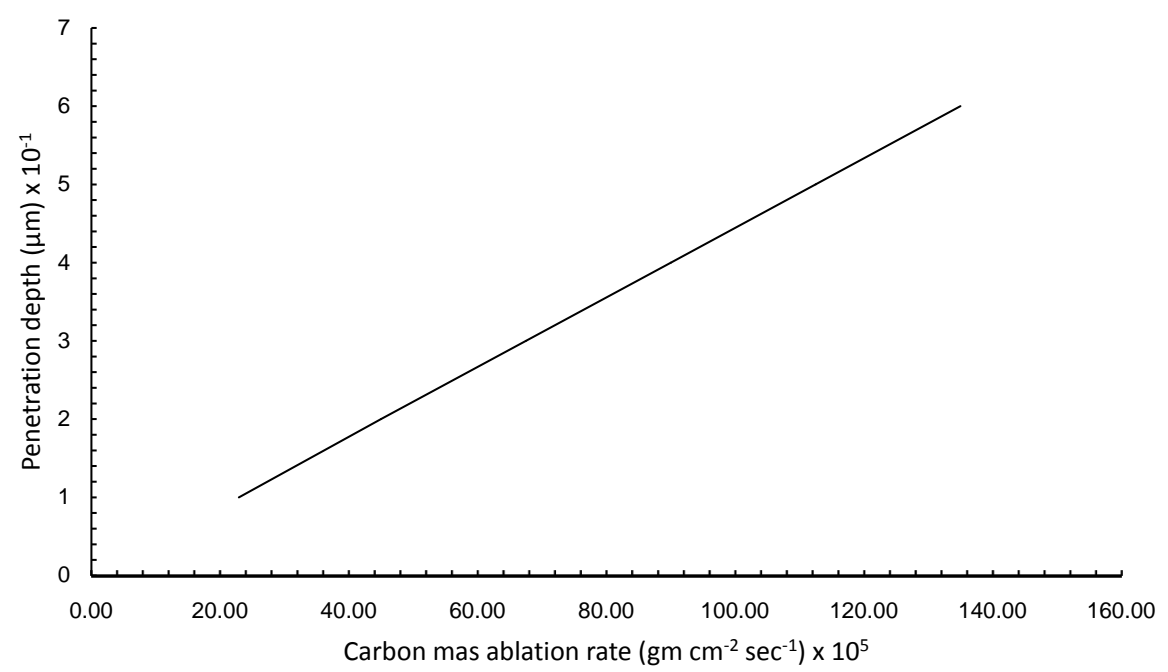

Figure 10. The calculated penetration depth into carbon target and the mass ablation rate ( $\dot{m})$.

distance, the angle between specimen and target normal to the laser, irradiance, the resist material and development procedure.

\section{Acknowledgements}

Authors acknowledge the contribution of Eng. Ibrahim A. Almujtaba and Eng. Mohammed Ashraf Ali in the production of the some drawings.

\section{References}

[1] Al-Hadithi, Y., et al. (1994) Energy Transport in Plasmas Produced by a High Brightness Krypton Fluoride Laser Focused to a Line. Physics of Plasmas, 1, 1279-1286. https://doi.org/10.1063/1.870726

[2] Basov, N.G. and Krokhin, O.N. (1964) Conditions for Heating up of a Plasma by the 
Radiation from an Optical Generator. Soviet Physics-JETP, 19, 123-125.

[3] Dawson, J.M. (1964) On the Production of Plasma by Giant Pulse Lasers. The Physics of Fluids, 7, 981-987. https://doi.org/10.1063/1.1711346

[4] Pile, D. (2015) Integrated Photonics: Compact Multiplexing. Nature Photonics, 9, 78-78. https://doi.org/10.1038/nphoton.2015.2

[5] Vergunova, G.A., et al. (2015) Soft X-Ray Spectrum of Laser-Produced Aluminum Plasma. Plasma Physics Reports, 41, 408-414. https://doi.org/10.1134/S1063780X15050086

[6] Ryazantsev, S.N., et al. (2016) Diagnostics of Laser-Produced Plasmas Based on the Analysis of Intensity Ratios of He-Like Ions X-Ray Emission. Physics of Plasmas, 23, Article ID: 123301. https://doi.org/10.1063/1.4971805

[7] Soloviev, A., et al. (2017) Experimental Evidence for Short-Pulse Laser Heating of Solid-Density Target to High Bulk Temperatures. Scientific Reports, 7, Article ID: 12144. https://doi.org/10.1038/s41598-017-11675-2

[8] Michette, A.G., et al. (1986) Soft X-Ray Contact Microscopy Using Laser Plasma Sources. Journal of Physics D: Applied Physics, 19, 363-372. https://doi.org/10.1088/0022-3727/19/3/008

[9] Eason, R.W., et al. (1986) Laser X-Ray Microscopy. Journal of Modern Optics, 33, 501-516. https://doi.org/10.1080/713821966

[10] Cheng, P.C., et al. (1986) Soft X-Ray Contact Microscopy. Nuclear Instruments and Methods in Physics Research Section A: Accelerators, Spectrometers, Detectors and Associated Equipment, 246, 668-674. https://doi.org/10.1016/0168-9002(86)90171-3

[11] O'neill, F., et al. (1986) X-Ray Lithography Using a KrF Laser-Plasma Source. Applied Optics, 25, 464-465. https://doi.org/10.1364/AO.25.000464

[12] Chao, W.L., et al. (2005) Soft X-Ray Microscopy at a Spatial Resolution Better than 15 nm. Nature, 435, 1210-1213. https://doi.org/10.1038/nature03719

[13] Schneider, G., et al. (2010) Three-Dimensional Cellular Ultrastructure Resolved by X-Ray Microscopy. Nature Methods, 7, 985-987. https://doi.org/10.1038/nmeth.1533

[14] Cappelli, E., et al. (2008) Critical Role of Laser Wavelength on Carbon Films Grown by PLD of Graphite. Applied Physics A: Materials Science \& Processing, 93, 751-758. https://doi.org/10.1007/s00339-008-4708-7

[15] Al-Shboul, K.F., Harilal, S.S. and Hassanein, A. (2011) Gas Dynamic Effects on Formation of Carbon Dimers in Laser-Produced Plasmas. Applied Physics Letter, 99, Article ID: 131506. https://doi.org/10.1063/1.3645631

[16] Reya, T., et al. (2001) Stem Cells, Cancer, and Cancer Stem Cells. Nature, 414, 105-111. https://doi.org/10.1038/35102167

[17] Yang, M.-H., Imrali, A. and Heeschen, C. (2015) Circulating Cancer Stem Cells: The Importance to Select. Chinese Journal of Cancer Research, 27, 437-449.

[18] Fabbro, R., et al. (1985) Experimental Study of Ablation Pressures and Target Velocities Obtained in $0.26 \mu \mathrm{m}$ Wavelength Laser Experiments in Planar Geometry. The Physics of Fluids, 28, 3414-3423. https://doi.org/10.1063/1.865342 